\title{
Confidence Testing of Shell 405 and S-405 Catalysts in a Monopropellant Hydrazine Thruster
}

\author{
Patrick McRight, ${ }^{*}$ Chris Popp, ${ }^{\dagger}$ Charles Pierce, ${ }^{\ddagger}$ and Alicia Turpin. ${ }^{\S}$ \\ NASA George C. Marshall Space Flight Center, Huntsville, AL, 35812 \\ Walter Urbanchock"* and Mike Wilson ${ }^{\dagger \dagger}$ \\ Aerojet, Redmond, WA, 98073
}

\begin{abstract}
As part of the transfer of catalyst manufacturing technology from Shell Chemical Company (Shell 405 catalyst manufactured in Houston, Texas) to Aerojet (S-405 manufactured in R edmond, W ashington), A erojet d emonstrated the equivalence of $S-405$ and Shell 405 at beginning of life. Some US aerospace users expressed a desire to conduct a preliminary confidence test to assess end-of-life characteristics for S-405. NASA Marshall Space Flight Center (MSFC) and Aerojet entered a contractual agreement in 2004 to conduct a confidence test using a pair of 0.2-lbf MR-103G monopropellant hydrazine thrusters, comparing S-405 and Shell 405 side by side. This paper summarizes the formulation of this test program, explains the test matrix, describes the progress of the test, and analyzes the test results. This paper also includes a discussion of the limitations of this test and the ramifications of the test results for assessing the need for future qualification testing in particular hydrazine thruster applications.
\end{abstract}

\section{Introduction}

F ollowing the Shell Corporation's decision to discontinue production of Shell 405 catalyst in 2002, aerospace users faced uncertainty regarding the continued availability of this alumina-based iridium catalyst which has for decades been used to decompose hydrazine in thrusters and auxiliary power units (APUs). With the ramifications of Shell's decision becoming clear, NASA's Marshall Space Flight Center (MSFC) and Kennedy Space Center (KSC) began work with Aerojet under contract number NAS8-02041 to assure timely and successful transfer of the catalyst manufacturing technology from S hell to Aerojet's Redmond, W ashington facility under the new name, "S-405." Throughout this technology transfer effort, a group of NASA users convened regularly to monitor progress, discuss concerns, and evaluate potential issues in the technology transfer. On March 13, 2003, this group held an on-site ineeting at Aecoojet Redinoñd to revicw the outcome of the technology transfer and to close out the NASA contract that enabled it. At the conclusion of the meeting, representatives concurred that the manufacturing technology had been successfully transferred and that test results proved that 14-18 mesh S-405 and Shell 405 had equivalent beginning-of-life (BOL) characteristics.'

Some users, among them NASA MSFC propulsion engineering, began to express a desire for data demonstrating the equivalence of Shell 405 and S-405 near the end-of-life (EOL). At a July 24, 2003 meeting of the United States S-405 user community, MSFC set forth a preliminary concept for a confidence test to provide insight into EOL characteristics. The purpose of this test would be to identify a well-characterized thruster with a low thrust level (to minimize propellant costs) that had been previously qualified using Shell 405 . Testing with S-405 would then provide a basis for comparison that could serve as an early exploratory test to uncover differences, if any, between the catalysts.

\footnotetext{
Deputy Chief, Spacecraft Propulsion Systems Branch, Mail Stop ER23, Member.

${ }^{\dagger}$ Aerospace Engineer, Spacecraft Propusion Systems Branch, Mail Stop ER23, Non-member.

¥ Aerospace Engineer, Spacecraft Propulsion Systems Branch, Mail Stop ER23, Non-member.

$\S$ Aerospace Engineer, Spacecraft Propulsion Systems Branch, Mail Stop ER23, Non-member.

"* Senior Project Engineer, Member.

${ }^{\dagger \dagger}$ Senior Project Engineer, Member.
} 
Iterative discussions over the next several months refined the initial test approach, leading to user group consensus and a decision to proceed in January, 2004. This paper highlights the selected test approach and presents the results and conclusions of the test, which, due to various funding difficulties and schedule delays, began in January, 2005 and concluded two months later.

\section{Test Approach}

The test approach continued to evolve for some time following the July, 2003 users meeting until LockheedMartin and RNR Engineering identified a pair of Aerojet MR-103G thrusters (see Figure 1) that would be available for continued testing after the conclusion of a Lockheed-Martin test in the same vacuum test position at Aerojet Redmond. Since the thrust level was low $\left(0.2 \mathrm{lb}_{\mathrm{f}}\right)$ and since several thousand $\mathrm{lb}_{\mathrm{r}}$-sec of impulse would be accumulated before the confidence test would begin, the total propellant cost and total test cost was compatible with NASA's limited funding. Further, since the MR-103G had proven treacherous for Shell 405 in previous years, the group agreed that the test would be likely to uncover differences, if any, between Shell 405 and S-405 at EOL.

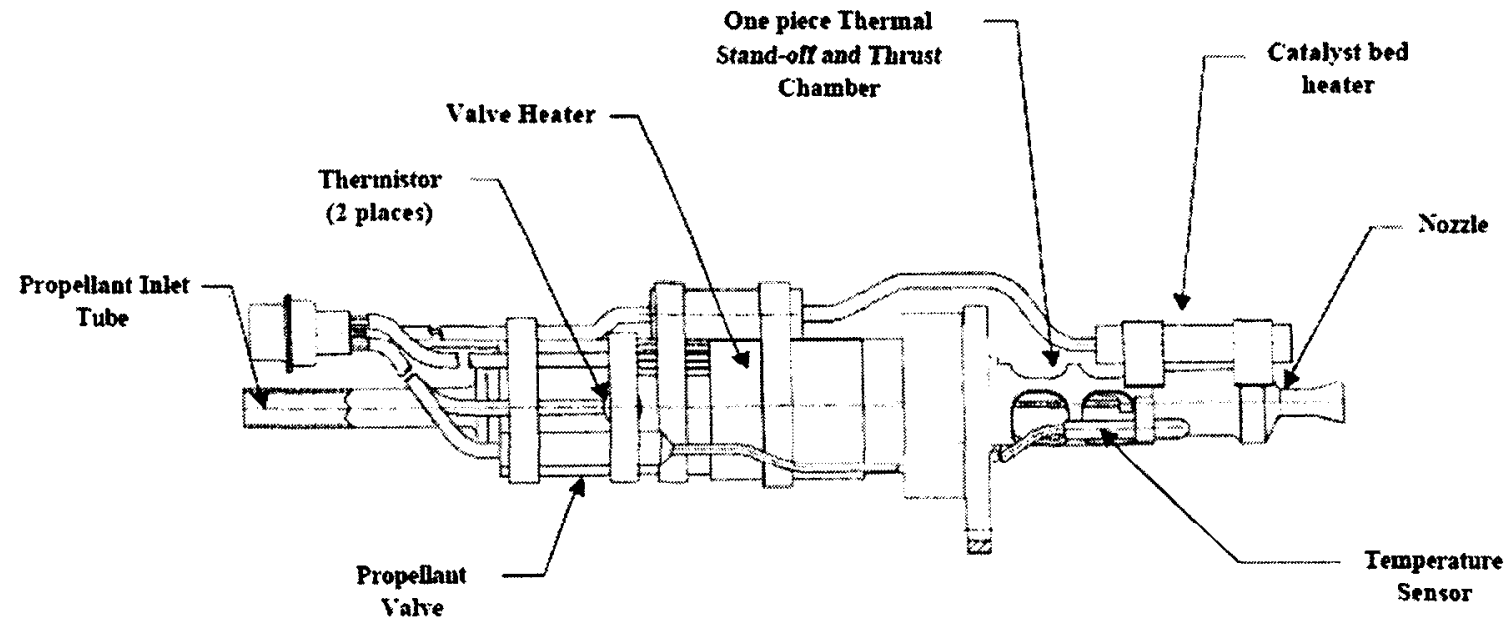

Figure 1. Depiction of MR-103G Thruster.

For clarity, the initial Lockheed-Martin test program will be referred to here as the "previous test program," whereas the subsequent testing will be called the "confidence test."

Figure 2 and Figure 3 illustrate the test conditions imposed in the previous test. As can be observed, the thruster burns were primarily long-duration (8-hour) continuous burns punctuated by periodic health checks.

Figures 4, 5, and 6 summarize the test conditions and flow for the confidence test. Pre-test evaluations included computer tomography (CT) scanning and functional checks (both electrical and mechanical). Unlike the previous test, the confidence test included a mixture of pulse mode operation ( 0.02 to 10 seconds "on") and periodic health checks. Following the side-by-side hot fire testing under vacuum conditions, post-test evaluations included the following: functional checks; CT scanning; disassembly and inspection; weighing and sieving the catalysts; Braunauer, Emmett, and Teller (BET) analysis; and hydrogen chemisorption testing. 


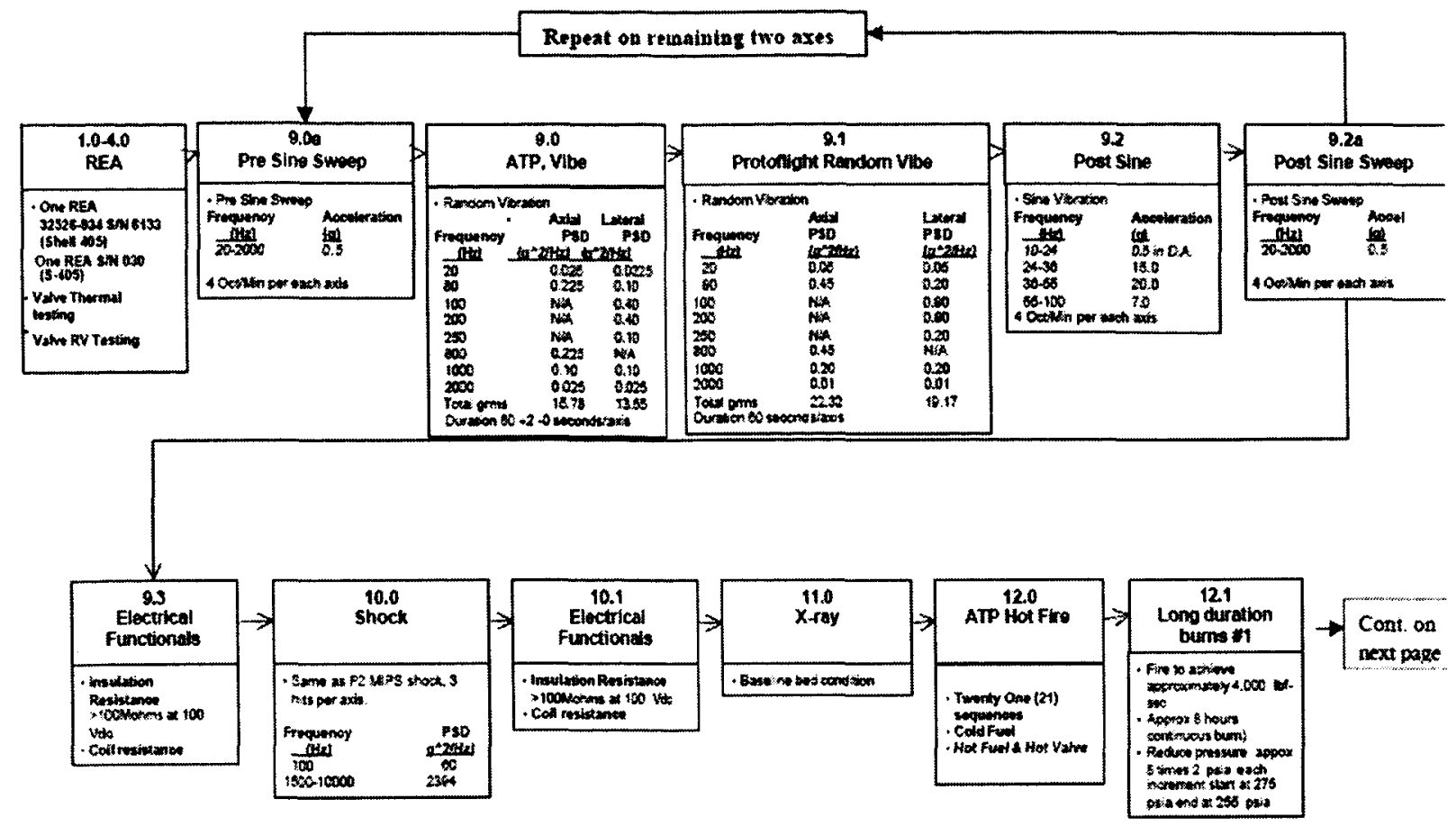

Figure 2. Previous Test Program Conditions and Flow (Part 1)

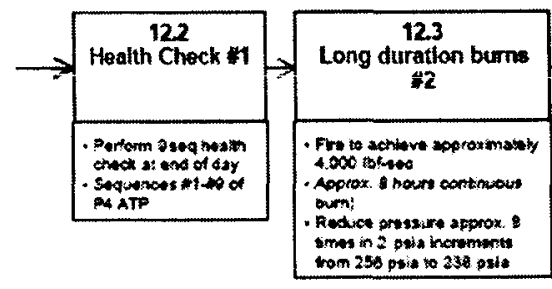

\begin{tabular}{|c|c|}
\hline $\begin{array}{c}124 \\
\text { Health Check i2 }\end{array}$ & $\underset{\substack{12.5 \\
\text { Long duration burns } \\
\$ 3}}{1.5}$ \\
\hline 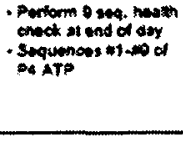 & 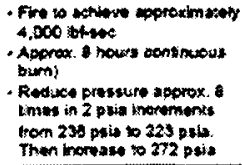 \\
\hline
\end{tabular}

\begin{tabular}{|c|c|}
\hline $\begin{array}{c}12,6 \\
\text { Health Check } * 3\end{array}$ & 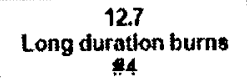 \\
\hline 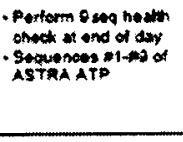 & 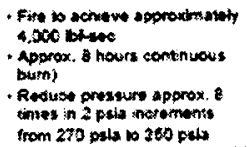 \\
\hline
\end{tabular}
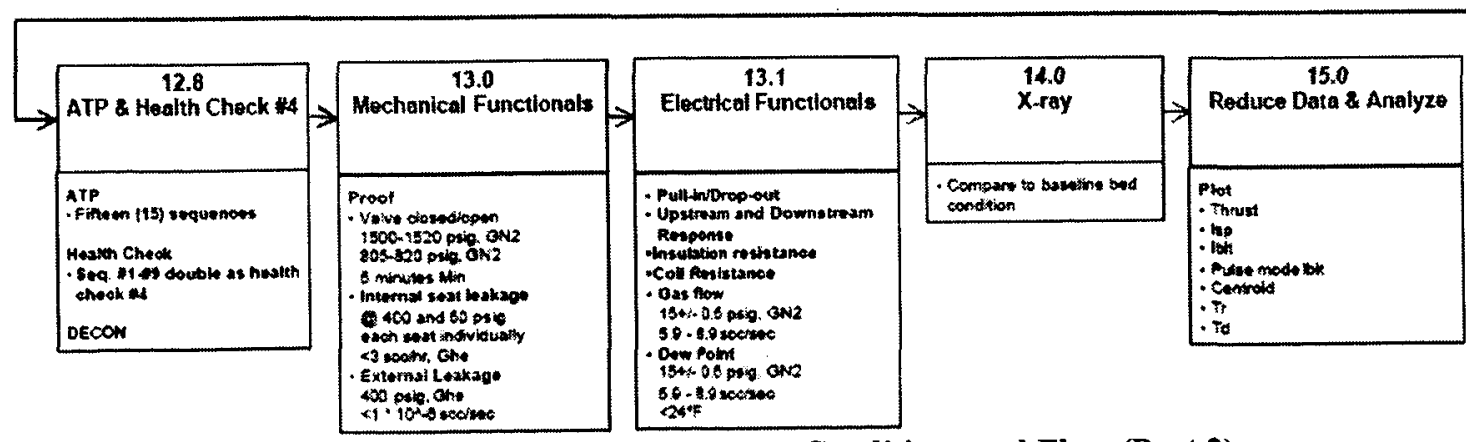

Figure 3. Previous Test Program Conditions and Flow (Part 2) 


\begin{tabular}{|c|c|c|c|}
\hline $\begin{array}{l}1,0 \mathrm{CT} \\
\operatorname{scan}\end{array}$ & $\begin{array}{l}\text { 20Reation } \\
\text { Valves }\end{array}$ & $\begin{array}{l}\text { 3.0 Mechanlcal } \\
\text { Funotional ohocks }\end{array}$ & $\begin{array}{l}\text { 3.1 Electrical } \\
\text { functlonal checks }\end{array}$ \\
\hline $\begin{array}{l}\text {-Perform CT } \\
\text { Scan of } \\
\text { thruster }\end{array}$ & $\begin{array}{l}\text {-Vane SIN } 5031 \\
\text { mated to } \\
\text { thnuster SN } 6133 \\
\text {-Valve SNN } 4066 \\
\text { mated to } \\
\text { thruster SN } 030 \\
\text { Same } \\
\text { valve/thruster } \\
\text { matching as previous } \\
\text { program }\end{array}$ & $\begin{array}{l}\text { Proot } \\
\text { Valve closediopen } \\
1500-1520 \text { psig. GN2 } \\
805-820 \text { psig. GN2 } \\
5 \text { minutes Min } \\
\text { Internal seat leakage } \\
\text { Q } 400 \text { and } 50 \text { psig } \\
\text { each seat Individualy } \\
<3 \text { scchr, Ghe } \\
\text { - External Leakage } \\
400 \text { psig, Ghe } \\
<1-10^{\wedge}-6 \text { sccisec }\end{array}$ & $\begin{array}{l}\text {-Pull-in/Drop-out } \\
\text {-insulation rusistance } \\
\text {-Coll Resistance } \\
\text {-Gas flow } \\
15+1-0.5 \text { psig. GN2 } \\
5.9-8.9 \text { sccisec }\end{array}$ \\
\hline
\end{tabular}

Figure 4. Test Conditions and Flow for the Confidence Test (Part 1)
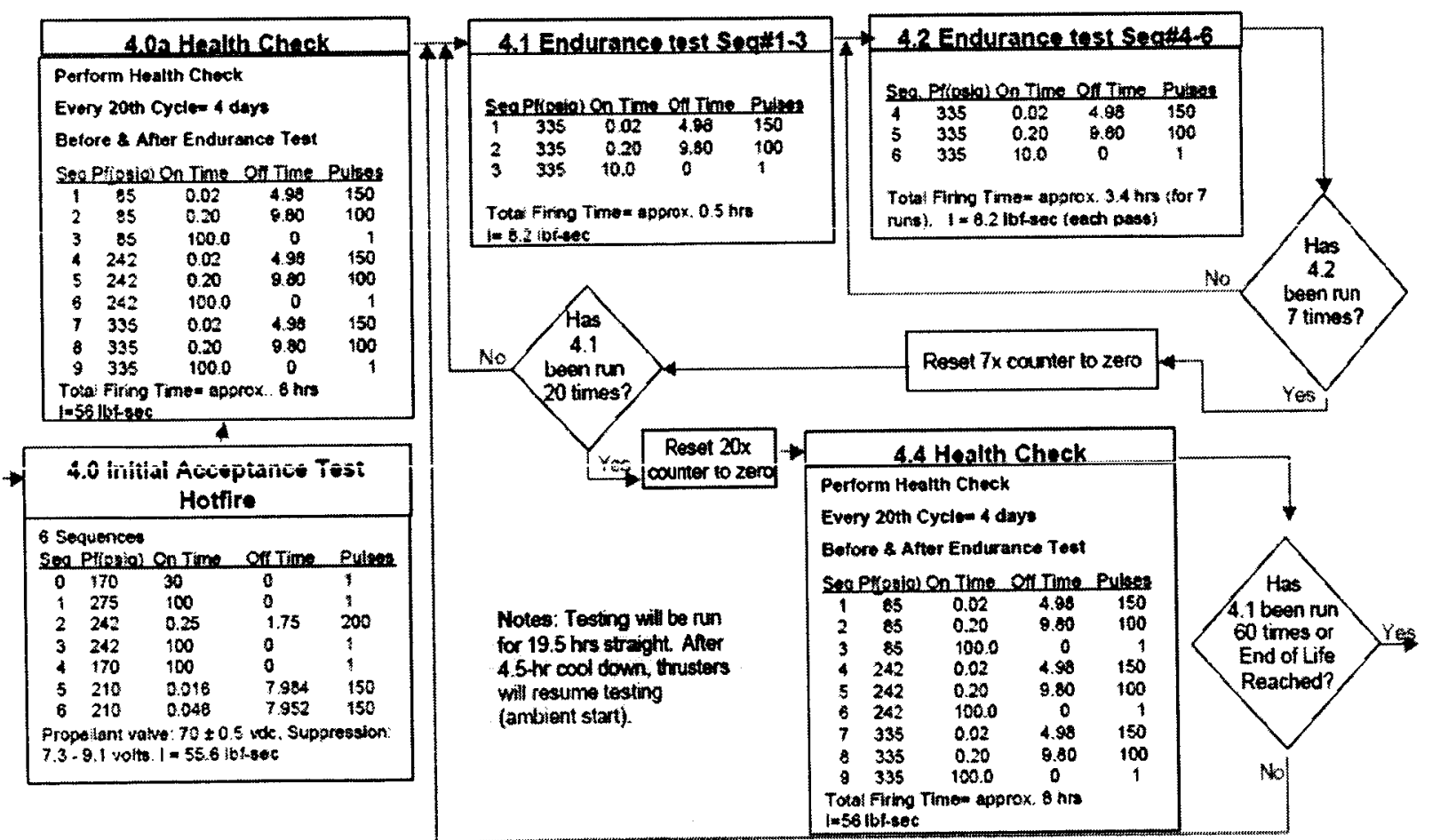

Figure 5. Test Conditions and Flow for the Confidence Test (Part 2) 


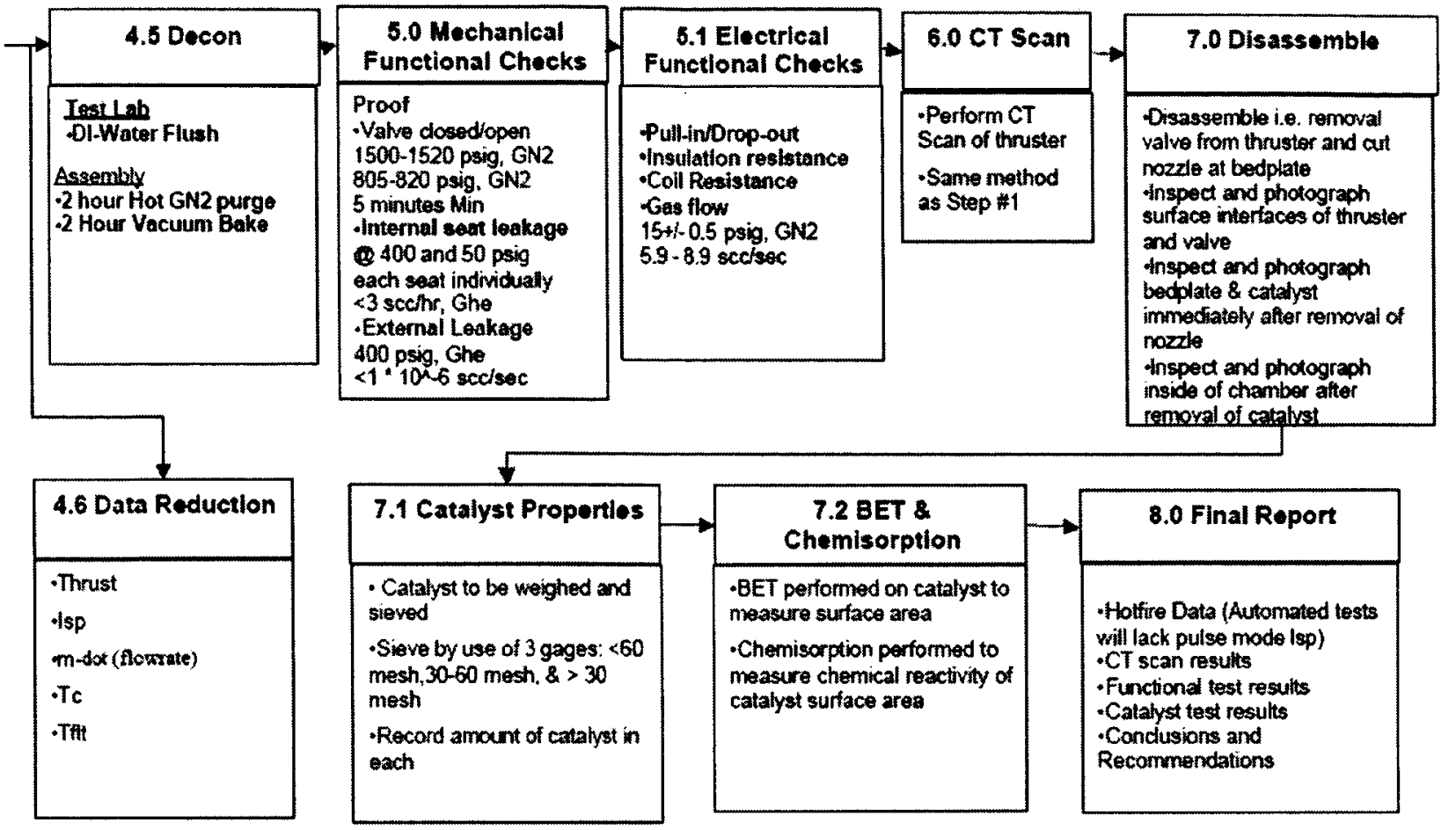

Figure 6. Test Conditions and Flow for the Confidence Test (Part 3)

\section{Test Results}

The previous testing and confidence testing demonstrated the capabilities of the two MR-103G thrusters shown in

Tabie i. Both thrusters successfulity compieted the hot fire test program, and all data was judged to be within historical parameters. Both thrusters intermittently experienced sining roughness, which is normal for the MR-103G thruster. In general, the S-405 thruster (S/N 030) appeared to sine more frequently. The health checks uncovered no unusual thermal operating conditions.

Evaluation of thrust vs. feed pressure and steady state specific impulse (Isp) vs. feed pressure indicated that both engines met BOL tolerances at both the beginning and end of the test. Steady state Isp was observed to dip below the minimum tolerance during the previous program's health checks. This behavior was attributed to the softness of the fuel system; the dissolved gas in the fuel affected both thrust and flow rate measurement.

Evaluation of thrust and Isp performance over the life of the thrusters indicated that performance differences were within typical engine-to-engine variation. At times, S-405 chamber pressure spiking was observed to a greater extent in the S-405 thruster (S/N 030).

In general there was no definitive pattern or trend observed apart from typical degradation associated with the accrual of life on the thrusters. Both thrusters experienced degradation in tail-off, due to formation of voids in the catalyst bed as life accrues. Data indicated no distinct trend in critical velocity (C-star). Also chamber pressure roughness had no pattern or trend observed apart from typical life degradation. Both steady state thrust levels and performance (Isp) levels were within BOL tolerances at the end of the test.

Pre-test CT scans of the Shell 405 thruster ( $\mathrm{S} / \mathrm{N} 6133)$ indicated a catalyst void of $0.4 \%$ of the total bed volume near the injector, while the post-test CT scan indicated voids totaling to $1.1 \%$ of the bed volume. On the other hand, the S-405 thruster (S/N 030) had no noticeable void in the pre-test CT scan, but had voids totaling $0.9 \%$ of the bed volume in the post-test scan. In general, the majority of post-test voids in both thrusters were near the injector. The scans were similar between the two thrusters, and the voids in both thrusters were judged to be in line with historical precedents.

The post-test disassembly and inspection revealed subtle differences in the condition of the two catalyst beds. The Shell 405 (S/N 6133) bed had a visibly observable void near the top of the catalyst bed, whereas the S-405 bed 
had no observable void. When catalyst granules were poured out, the Shell 405 granules stuck together, indicating that sintering had occurred in the bed. S-405, however, poured freely (no sintering observed). Both thrusters exhibited typical chamber and bedplate discoloration and catalyst markings in the chamber.

BET testing indicated a higher BET value for S-405 than Shell 405 in the upstream portion of the beds. In the downstream portion of the beds, the opposite trend was observed. Post-test chemisorption analysis of both catalysts exceeded the typical value of $90 \mu$ mole $\mathrm{H}_{2} / \mathrm{g}$.

Table 1. Demonstrated Capabilities

\begin{tabular}{|c|c|c|}
\hline & Shell 405 Thruster (S/N 6133) & $\mathrm{S}-405$ Thruster (S/N 030) \\
\hline $\begin{array}{l}\text { Total pulse count } \\
\text { Previous Test } \\
\text { Confidence Test } \\
\text { Total }\end{array}$ & $\begin{array}{r}9,641 \\
124,010 \\
133,651 \\
\end{array}$ & $\begin{array}{r}10,044 \\
124,010 \\
134,054 \\
\end{array}$ \\
\hline Number Of Ambient Starts & 12 & 12 \\
\hline $\begin{array}{l}\text { Cumulative Total Impulse }\left(\mathrm{lb}_{\mathbf{r}}-\mathrm{sec}\right) \\
\text { Previous Test } \\
\text { Confidence Test } \\
\text { Total }\end{array}$ & $\begin{array}{r}19,336 \\
3,841 \\
23,177\end{array}$ & $\begin{array}{r}18,370 \\
3,812 \\
22,182\end{array}$ \\
\hline Longest Continuous Burn & 8 hours 10 minutes ${ }^{\mathrm{a}}$ & 8 hours 10 minutes $^{\mathrm{a}}$ \\
\hline Lowest Rate Duty Cycle Tested & $\begin{array}{r}0.16 \%(0.016 \mathrm{sec} \text { on } \\
9.984 \mathrm{sec} \text { off }) \\
\end{array}$ & $\begin{array}{r}0.16 \%(0.016 \mathrm{sec} \text { on } \\
9.984 \mathrm{sec} \text { off }) \\
\end{array}$ \\
\hline Minimum Pulse Width (sec) & $0.016^{\mathrm{a}}$ & $0.016^{\mathrm{a}}$ \\
\hline Inlet Pressure Range (psia) & $100-350$ & $100-350$ \\
\hline Fuel Temperature & $\begin{array}{r}12-60^{\circ} \mathrm{C}^{a} \\
\left(54^{\circ} \mathrm{F}-140^{\circ} \mathrm{F}\right) \\
\end{array}$ & $\begin{array}{r}12-60^{\circ} \mathrm{C}^{\mathrm{a}} \\
\left(54^{\circ} \mathrm{F}-140^{\circ} \mathrm{F}\right) \\
\end{array}$ \\
\hline Valve Voltage Range (Vdc) & $\begin{array}{r}70-71 \\
\text { Seats wired in series }\end{array}$ & $\begin{array}{r}70-71 \\
\text { Seats wired in series }\end{array}$ \\
\hline Valve Suppression Voltage (Vdc) & 8.2 & 8.2 \\
\hline Change in Thrust @ 257 psia $^{\mathrm{b}, \mathrm{c}}$ & $-3.6 \%$ & $-4.3 \%$ \\
\hline Change in $I_{\text {sp }} @ 257$ psia $^{6}$ & $-0.2 \%$ & $-0.3 \%$ \\
\hline Change in Roughness @ 257 psia $^{b}$ & $+1.5 \%$ & $+3.8 \%$ \\
\hline \%Catalyst Void (CT scan after all testing) & $1.1 \%$ & $0.9 \%$ \\
\hline $\begin{array}{l}\% \text { Catalyst Void (By weight after all } \\
\text { testing) }\end{array}$ & $2.5 \%$ & $0.6 \%$ \\
\hline$\Delta \mathrm{BET}$, Upstream Bed $\left(\mathrm{m}^{2} / \mathrm{g}\right)$ & -7 & -8 \\
\hline$\triangle B E T$, Downstream $\left(\mathrm{m}^{2} / \mathrm{g}\right)$ & -4 & -8 \\
\hline $\begin{array}{l}\Delta \text { Chemisorption, Upstream Bed } \\
\left(\mu \text { moles } \mathrm{H}_{2} / \mathrm{g}\right)\end{array}$ & -27 & -26 \\
\hline $\begin{array}{l}\Delta \text { Chemisorption, Downstream Bed } \\
\left(\mu \text { moles } \mathrm{H}_{2} / \mathrm{g}\right)\end{array}$ & -18 & -17 \\
\hline
\end{tabular}

\section{Conclusions}

Based on these test results, the investigators have concluded that Shell 405 and S-405 catalysts provide equivalent performance near the end of life in an MR-103G 0.2-1b thruster. Differences observed between these two thrusters are consisted with thruster-to-thruster variations. 
It is appropriate to mention the limitations of this test program. While the user community generally concurred with the test approach reported here would be a useful exploratory test, there was also general consensus that no single test could assure S-405 equivalence for all thruster and APU applications. Hence, it must be emphasized that the intent of this test was to provide data that could be used as a basis for assessing confidence in S-405's EOL properties. While the positive test results may enhance confidence in the quality of S-405, MSFC does not intend for the test results to be used to certify S- 405 as a "drop-in replacement" for Shell 405 for all applications and usage scenarios.

\section{Acknowledgments}

The authors gratefully acknowledge the kind assistance of Mr. Chris Singer, Deputy Director of the MSFC Engineering Directorate and Mr. Phil Best, Project Manager, for their kind assistance enabling the completion of this project.

\section{References}

\footnotetext{
${ }^{1}$ Wucherer, E. J., Cook, T., Stiefel, M., Humphries, R., and Parker, J. "Hydrazine Catalyst Production: Sustaining S-405 Production Technology", AIAA 2003-5079, 39th AIAA/ASME/SAE/ASEE Joint Propulsion Conference \& Exhibit, Huntsville, AL, July 20-23, 2003.
} 